\title{
Social Status Polarization in the Timing and Trajectories to Motherhood
}

\author{
Zenaida R. Ravanera \\ Fernando Rajulton \\ Population Studies Centre \\ University of Western Ontario \\ London, Ontario, Canada
}

\begin{abstract}
:
This paper examines the polarization by social status of Canadian women's timing and trajectories to motherhood. The study applies event history analysis on data gathered through the 2001 General Social Survey on Family History and focuses on women born from 1922 to 1980 . Women with high social status are more likely to delay their entry into motherhood and to follow normatively preferred trajectories that include graduation from post-secondary education. In contrast, women with low social status are more likely to follow shorter routes, often bypassing graduation from post-secondary education, regular work, or marriage, and consequently become mothers at younger age.
\end{abstract}

Key Words:: life course, social status polarization, onset of motherhood, transition to adulthood, event history analysis, trajectory analysis, timing of fertility 


\section{Résumé:}

Cet article examine la polarisation par statut social du choix du moment et du parcours de la maternité chez les Canadiennes. Cette étude s'appuie sur une analyse biographique de données récoltées en 2001 pendant l'Enquête sociale générale de la rétrospective sur la famille et porte sur les femmes nées entre 1922 et 1980. Les femmes de statut social élevé tendent à reculer leur première maternité et à suivre un parcours de vie qui inclue l'acquisition d'un grade postsecondaire et qui sont normalement plus favorisés par la société. Par contraste, les femmes de statut social plus bas ont une plus forte tendance à suivre un parcours qui souvent court-circuite les études post-secondaires, un emploi régulier ou le mariage, et par conséquent, elles commencent souvent leur maternité à un plus jeune âge.

Mots-clés: le cours de la vie, la polarisation de statut social, le début de la maternité, l'analyse biographique, l'analyse de parcours, le moment de la fertilité

\section{Introduction}

In Europe, there is a concern over polarization of family life among the younger generations: on one end are those who 'invest in children and partnership', and on the other, those who forsake children, partnership or both in favour of selfactualization (Schulze and Tyrell, 2002, p. 77 citing Kaufmann, 1988). The split is not seen merely as a differentiation in orientation; that is, among those childoriented, partner-oriented, or individualistic. Rather polarization is the accentuation of the differences in family life or demographic behaviour (such as those related to fertility and family dissolution) by differences in social and economic dimensions, indicated for example, by income, class or life styles (Schulze and Tyrell, 2002, p. 78).

A similar concern is echoed in the United States. As Suzanne Bianchi notes, there may be a bifurcation of parents and children into two groups: children brought up by two parents who are able to devote time and money to parenting, and children raised by mothers, with fathers absent, who have inadequate resources (Bianchi, 2000). Parents of the first group are generally highly educated and tend to delay childbearing to older ages (Martin, 2000). This bifurcation is observed in Canada as well. Lochhead (2001), for example, finds that those who become parents early have generally lower education and lower income than those who delay entry into parenthood, and that this difference is wider today than in the 1970s. 
Both polarization and bifurcation hypotheses have in common the intensification of differences in family life by disparities in socio-economic conditions. But there is difference in emphasis: 'polarization' makes more explicit the relation between social inequality and family life. Schulze and Tyrell, for instance, find evidence using data from European countries in the 1980s that families are formed mainly by those in the lower social class whose economic condition is made more precarious by their having children. Further, they conjecture that those who form families have traditional orientation and are 'less affected by cultural liberalization and by enlargement of options than are middle class people' (Schulze and Tyrell, 2002, p. 84). The bifurcation theory, on the other hand, puts more emphasis on the consequences, that is, on the impact of inadequate inter-generational transfers or investment on children among those who have children at an early age, who tend to have low education and income, and also more likely to divorce. Thus, Lochhead (2000) finds that parental education, family income, and parenting practices are all significantly related to children's outcome and proposes that this may be connected to an emerging bifurcation of fertility.

Drawing upon the polarization and bifurcation hypotheses, we examine the timing and trajectories toward first birth with the assumption that social status differentiates family life and other early life events such as attainment of education and entry into the labour force. Further, we assume that one's socioeconomic status, and consequently, the polarization in the demographic sphere, is largely influenced by parental social status through inter-generational transfers or parental investment on children. In this study, we focus on the influence of parents on the subjects' life courses rather than the subjects' influence on their own children's outcome. The study examines cohorts of women born from 1922 to 1980, allowing us to detect changes over time.

\section{Polarization of the Life Course}

The onset of parenthood is linked to other early life course transitions that comprise the transition to adulthood. Birth of first child could be considered as the culmination of the transition to adulthood that includes other important early life course events such as completion of schooling, start of regular work, and entry into marital union. Factors that influence the timing of parenthood may be similar to those affecting the other transitions and may be mediated by these earlier transitions.

Canadians born since the mid 1960s have made the transition to adulthood at later ages than those born earlier, which has happened in other Western countries as well (Ravanera, Rajulton, and Burch, 1998; Ravanera et al, 2002; 
Fussell, 2002). Young Canadians complete a higher level of education and enter the work force at later ages, stay in parental homes longer, and delay union formation and start of parenthood (Lapierre-Adamcyk, Le Bourdais, and Lehrhaupt, 1995; Boyd and Norris, 1999; Ravanera, Rajulton, and Burch, 1995, 1998; Ravanera et al. 2002). However, the timing and trajectories to adulthood have varied within cohorts as these are influenced by factors such as individual and parental characteristics (Shanahan, 2000; Booth, Crouter, and Shanahan, 1999 and articles therein).

That social status differentiates the timing of transitions and life course trajectories is not a recent phenomenon. Studies in the United States show, for example, that the order of transitions has varied by social class within cohorts (Hogan, 1981; Hogan and Astone, 1986; Marini, 1984a). The normative sequence (completing schooling before marrying, for example) is more likely experienced by those in higher social class. Consequently, they are also less likely to experience negative consequences in later life such as marital instability (Hogan, 1980; Hogan and Astone, 1986, but see Marini, 1984b). In this study, rather than simply examining differentials by level of education that is often used as an indicator of social status, we focus on parental social status as a context in which to view the life course of individuals. Acquiring education, while important particularly for establishing one's own social status, is taken here as just one of the events within a young person's life trajectory.

In the next section we discuss the data and methods used in this study. We then present the results of our analysis in two parts - first, the timing differentials by social status and by cohort in the onset of motherhood and other related life course events; and second, the trajectories to motherhood passing through graduation from post-secondary education, start of regular work, and marriage. Explanations for the findings follow the presentation of results. The paper concludes with a discussion of the context of the recent interest in polarization and implications for policies.

\section{Data and Methods}

The study uses the 2001 General Social Survey on Family History, a countrywide survey conducted by Statistics Canada with a representative sample of those aged 15 and older, excluding residents of Yukon, Northwest Territories, and Nunavut and full-time residents of institutions (Statistics Canada, 2003). The survey has 24,310 respondents; however, we limit our study to women born from 1922 to 1980 , or 11,780 (weighted) respondents. Information gathered by the survey includes various aspects of the family including parents, children, union histories, fertility, and socioeconomic variables. The survey also 
collected education and work histories. In this study, we make use of retrospective information on age at birth of first child and age at experience of other events such as home-leaving, entry into the labour force, first union, and first marriage. These are obtained from questions on dates when the events occurred in conjunction with the date of birth of the respondent, yielding the ages at experience of these events.

The social status variable was derived from two parental variables, mother's education and father's occupation when the respondent was aged 15. Education and occupation, together with asset ownership, are often used as indicators of social class (Grabb, 2002: 224-228) and, information from the survey shows that most respondents seem to know their mother's education and their father's occupation. Parental social status is assumed to be relevant to the respondents' early life transitions, when the respondents themselves start the process of establishing their own social status. For this reason, and because the information was gathered through the survey, we consider parental status when the respondent was aged 15, and not at earlier ages. The mother's education and father's occupation were ranked into low, middle, and high and then combined to obtain the social status variable ${ }^{1}$. Where mother's education is missing, the measurement of social status is based only on father's occupation, which could shift a small percentage of respondents to a category lower than what would have been assigned had information on mother's education been available. (Appendix Table 1 shows some descriptive statistics about the sample including social status).

We analyzed the data using the following methods for event-history analysis.

1. To explore the differentials in the onset of motherhood by social status, we constructed single-decrement life tables of age at first birth using SPSS. As in the subsequent analyses, life tables were built separately for birth cohorts - 1922-40² (with 2224 respondents), 1941-60 (4646), and 1961-80 (4909), as cohorts go through different historical events that impact on their life courses (Ryder, 1965; Elder, 1978). It would be ideal to study narrower birth cohorts, for example 5 or 10 -year birth cohorts, but the necessity of working with adequate sample sizes does not allow this. In the discussion of the results from these life tables, we use mainly the median ages at birth of first child.

2. As a preliminary step to doing the trajectory analysis, we did life table analysis also for other early life course events - home-leaving, graduation from post-secondary education, start of regular work, first union, and first marriage. 
3. The trajectories through four life course events - education, work, marriage, and first birth (also referred to as "states") - are traced for respondents of different parental social statuses. For this procedure, we used the LIFEHIST program that computes the conditional probabilities of making specific trajectories to parenthood on the assumption that past history is important, which is known as a nonMarkovian assumption (Rajulton, 2001). Essentially, the procedure is a multiple-decrement life table technique that estimates the conditional probabilities of transition to each state and the mean duration of stay in each state. For our purpose, we focus on two specific results: (a) the probabilities of experiencing selected pathways or trajectories; and (b) the age at which the specific trajectory is completed.

In this study we use individual (fractional) sampling weights in all statistical procedures. This is necessary as Statistics Canada uses complex sampling procedures for its surveys (Statistics Canada, 2003).

The retrospective information used in the analysis has its limitations. There could be errors in recalling events that have occurred in the past; and as mortality rates are generally higher among those in the lower status, the sample may overly represent those in the higher social statuses. The bias caused by the first limitation may be small because dates of important life events are generally well remembered. As for the second limitation, the effect would be mainly in the estimates of those in the oldest cohort. And, if such a bias does exist, it would be toward a more conservative estimate of the differentials; that is, had the sample been more representative, the differentials would probably be greater.

\section{Results of Life Table Analysis}

\section{Change in Timing of Motherhood initiated by High Social Status Women}

As shown in Figure 1, high status women tended to start motherhood later than women of lower status in all cohorts ${ }^{3}$. This tendency was accentuated with a dramatic increase among high social status women born in 1941-60. Whereas in the oldest cohort (1922-40) there was only about a year that differentiated the high status women (25.8) from women of low status (24.3), in the mid-cohort (1941-60) the gap increased to 4.3 years (28.7 among high against 24.4 among those with low status). While there was a large increase in age from the oldest to the mid-cohort among high status women (that is, from 25.8 to 28.7 years), there was virtually no change among women with low social status. 


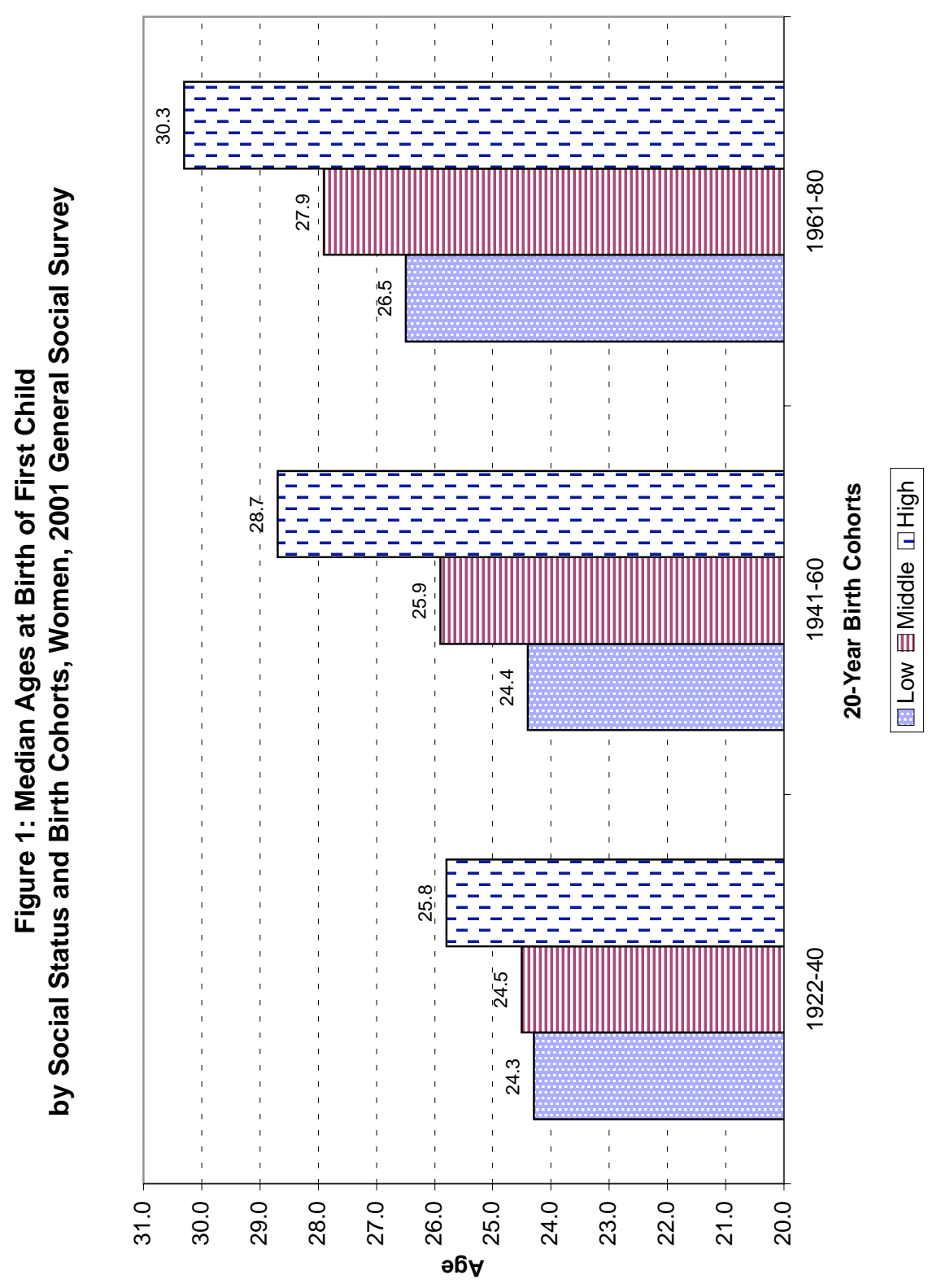


But, change did occur among women with lower status in the youngest cohort. The median ages at onset of motherhood increased by two years among low (from 24.4 to 26.5) and middle status women (from 25.9 to 27.9). However, the median age among the high status women increased as well (by about a year and a half; that is from 28.7 to 30.3) over those of the mid-cohort. Thus, the gap between high and low status women in the median age at onset of motherhood remains sizable (at 3.8 years) even among the youngest cohort.

\section{Onset of Motherhood Embedded in the Life Course}

The changes over cohorts and the differences by social status happened not only for the timing of first birth but also, as shown in Table 1, for other events that usually happen in early life. This indicates that the onset of parenthood is embedded in the life course and that its timing is closely related to that of other life events and, as will be shown in the next section, to the sequences of experiencing these events.

An important early life event is completion of schooling. As seen in Table 1, however, there is almost no difference in median age at graduation from postsecondary education by cohorts or by social status. This is because the survey asked the age at completion of first episode of post-secondary education only from those who graduated. Those who did not pursue or did not complete postsecondary education were not asked the dates when they stopped schooling. Even with this limitation, however, we were able to still make use of this information in the analysis of trajectories to motherhood (see below).

Like the onset of motherhood, in general, there has been an increase over cohorts in the average age at experience of all the other early life course events from home-leaving to first marriage (Table 1). In all three cohorts, the order of the median ages at experiencing the events is almost similar. The only difference in sequence is in the timing of the start of regular work and home-leaving: in the two oldest cohorts, on the average, start of regular work happens before leaving the parental home whereas in the youngest cohort, home-leaving precedes work start. Moreover, in the youngest cohort, the average ages at start of work and first union are virtually the same, while the age at first marriage is much higher than the age at first union. The latter is an indication of the widespread occurrence of cohabitation in the youngest cohort.

Women of high social status experience all the early life events at later ages than those from lower statuses (Figures $2 \mathrm{~A}$ to $2 \mathrm{C}$ ). In the oldest cohort, the median ages are not too different for the low and middle status women; the differences between these two statuses emerge only in the two younger cohorts. Moreover, 


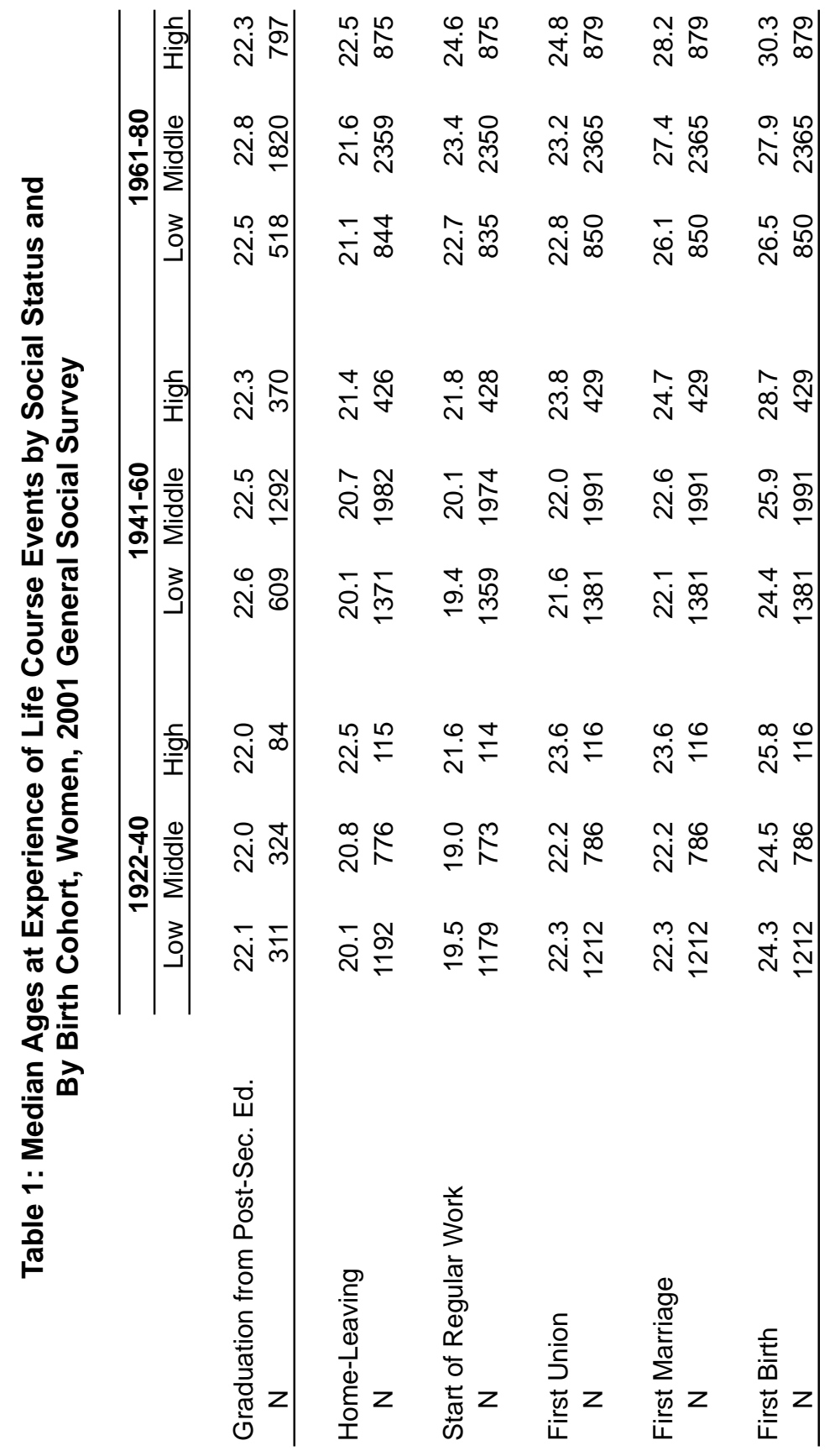


in the two younger cohorts, the difference by social status in the age at birth of first child is greater than the differences in the other events, with home-leaving showing the least difference. This indicates that the difference by social status in age at onset of motherhood is only partly accounted for by the differences in ages at experience of prior events.

Insights can be obtained from the average ages of various early life events; however, this type of information is not very useful for understanding the relations among the various events. Not all women experience all the events and many do not go through the events in the sequence implied by the average ages. To get a better understanding of the inter-relation among the various events, we refine our analysis by tracing the pathways toward motherhood, the results of which are presented in the next section.

\section{Results of Trajectory Analysis}

A trajectory analysis follows members of a cohort through the various events that they experience (or "states" that they occupy). These states need to be judiciously chosen since a large number of states would invariably lead to an unmanageable number of trajectories and would require a large number of cases for a proper analysis. This need is particularly difficult to meet when members of each cohort are categorized further, here, by social status. On the basis of the results of life table analysis discussed above, we select only three other life course events in addition to first birth: (a) graduation from first post-secondary education, (b) start of regular work, and (c) first marriage. We excluded first union in favour of first marriage because if a trajectory does not pass through the marriage state, it can be inferred that the birth occurred within a cohabiting union (except when the marriage dates are missing). For a similar reason, we included graduation from first post-secondary education as its absence in a trajectory implies the non-completion of tertiary education.

Tables $2 \mathrm{~A}, 2 \mathrm{~B}$ and $2 \mathrm{C}$ show the conditional probabilities of transitions from one state to another, the standard errors of these probabilities, and mean duration of stay in each state. These conditional probabilities have been corrected for censoring and thus provide the best possible estimates of true probabilities (unless there is very heavy censoring) ${ }^{4}$. Multiplication of these conditional probabilities in a specific trajectory provides an estimate of the trajectory's final probability of transition to first birth. And, summing up the mean durations of stay in each state provides a good estimate of the mean age at transition to first birth (since the means are computed from the conditional probabilities that have been corrected for censoring). Tables $2 \mathrm{~A}, 2 \mathrm{~B}$ and $2 \mathrm{C}$ show only the first five most common trajectories to motherhood, and the direct transition to 
Zenaida R. Ravanera and Fernando Rajulton
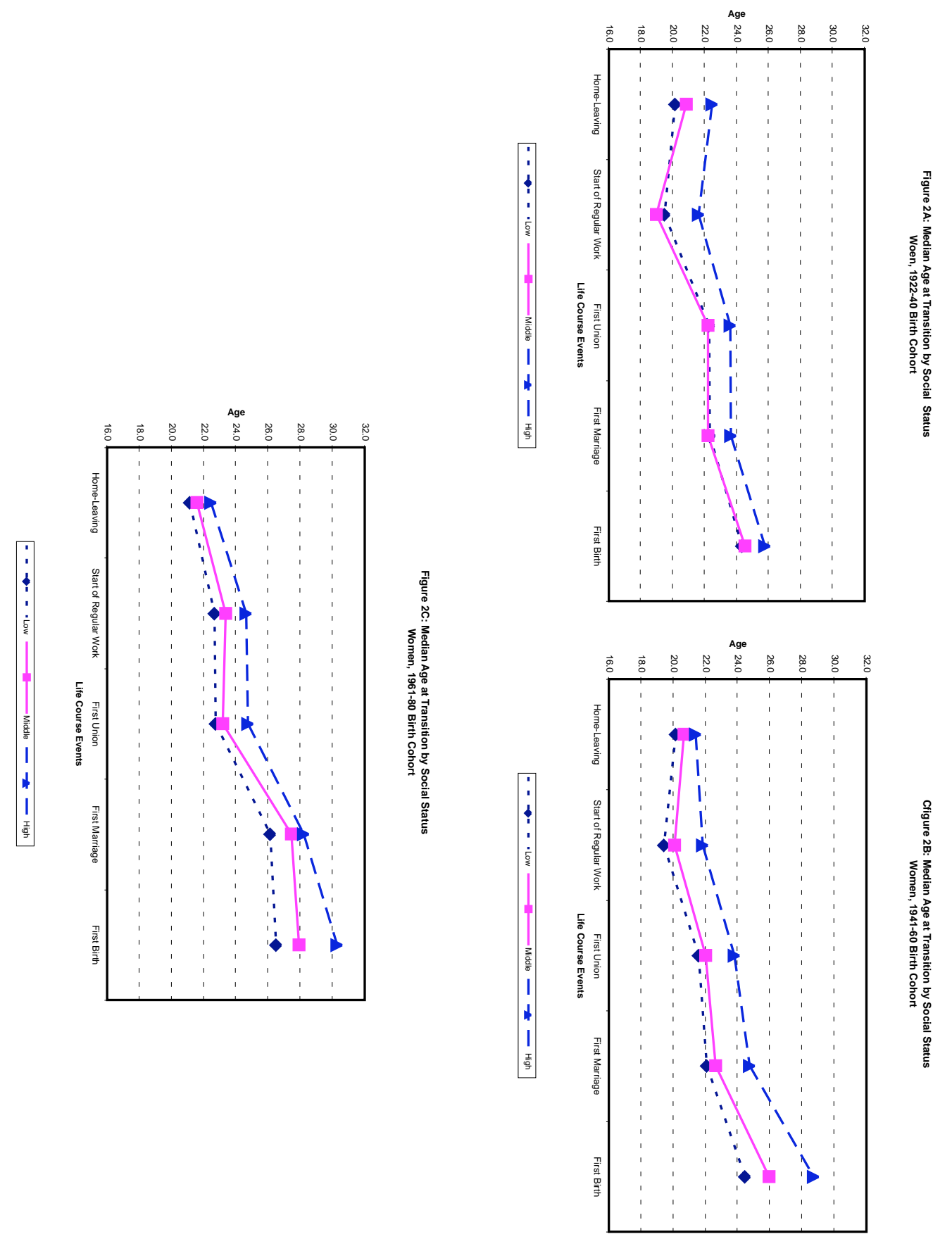

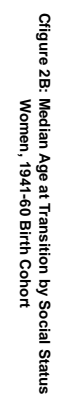




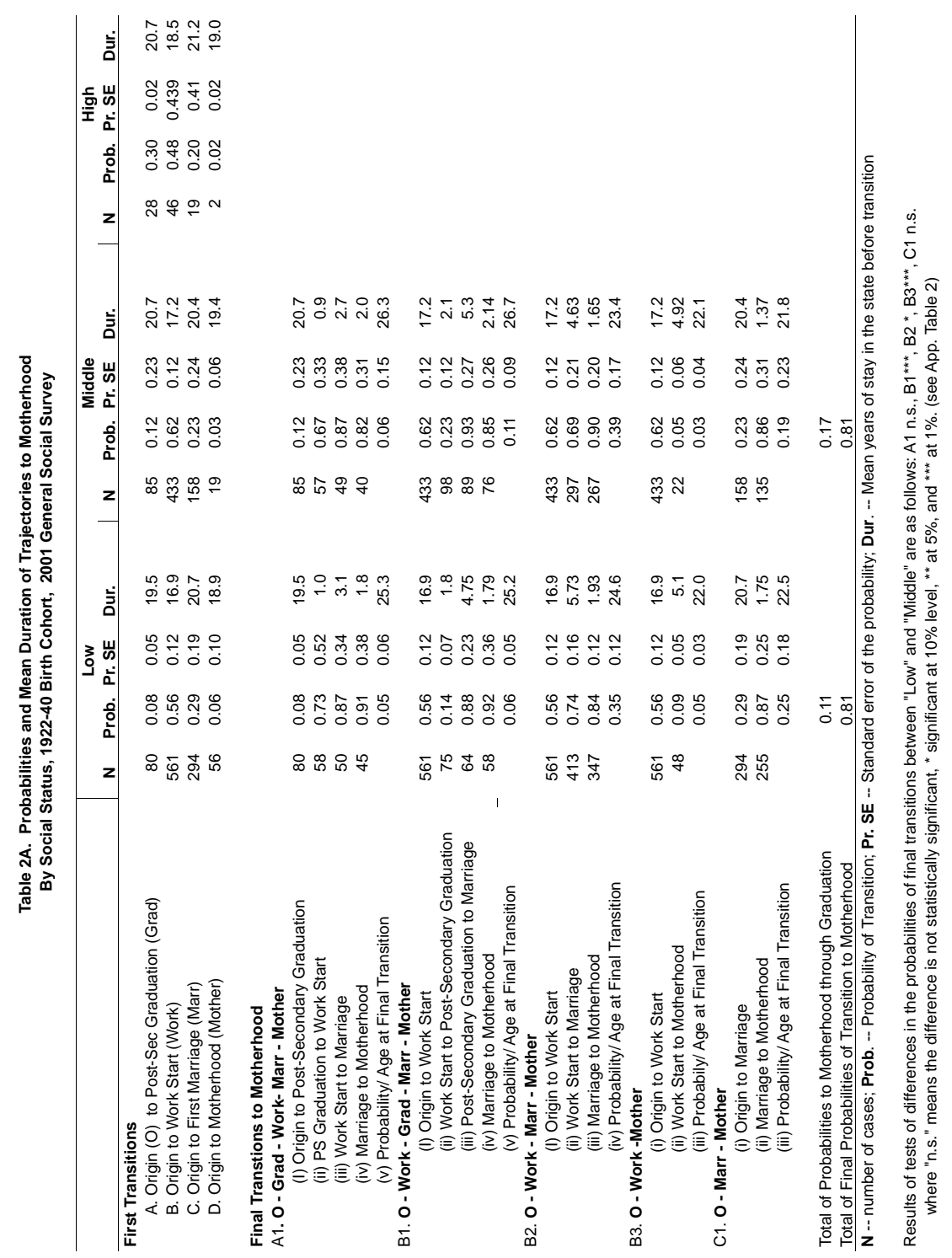


Zenaida R. Ravanera and Fernando Rajulton

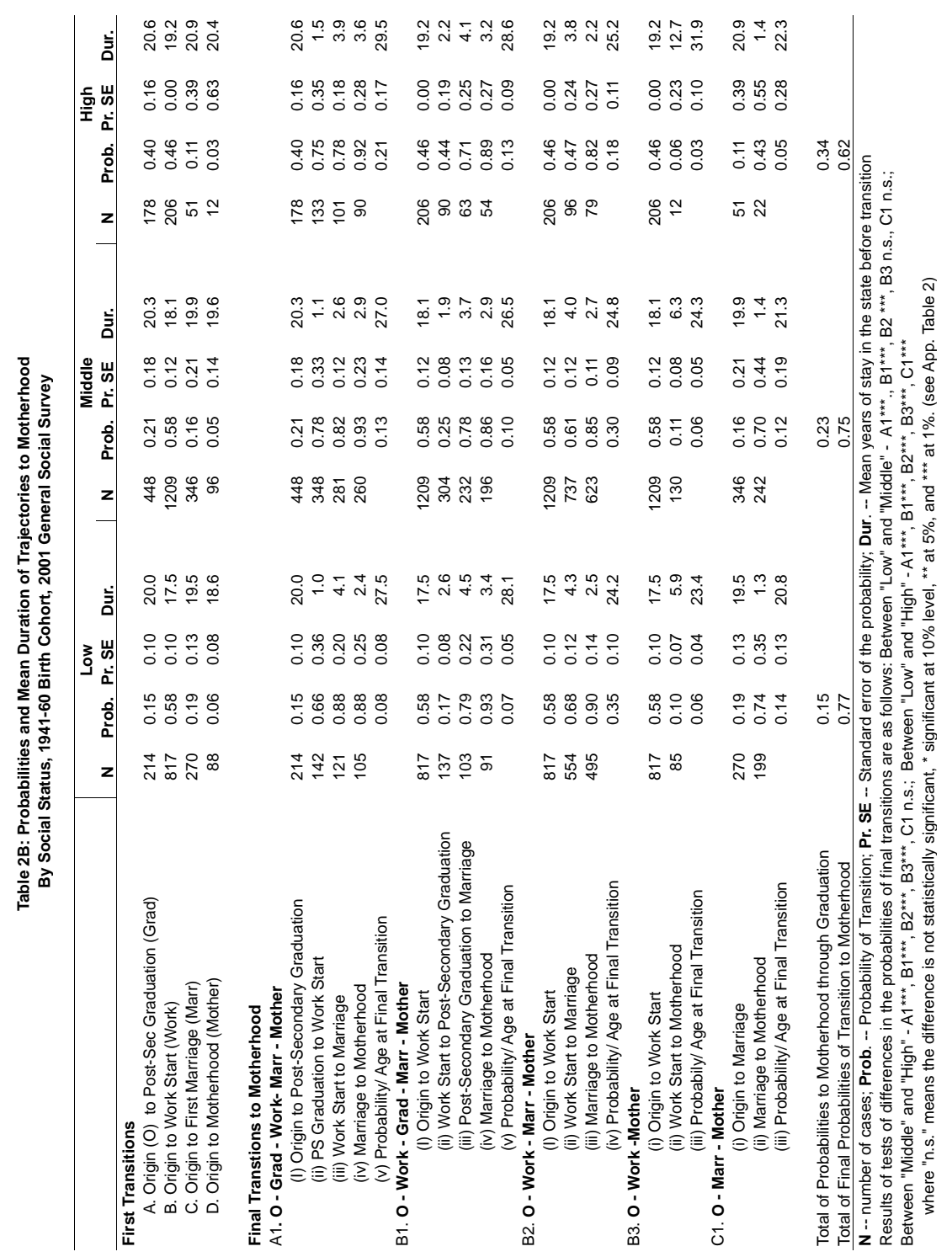


Social Status Polarization in the Timing and Trajectories to Motherhood

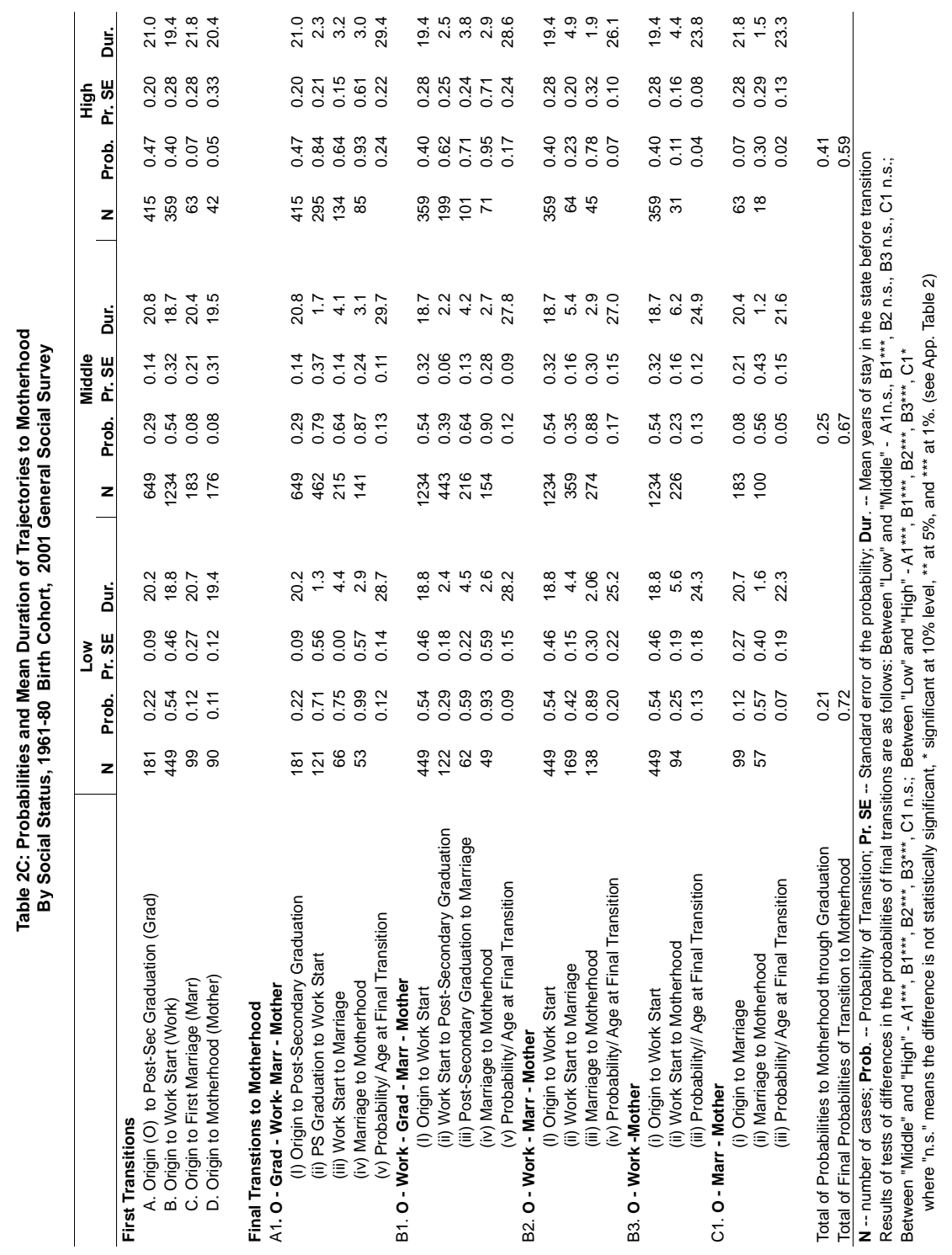


Social Status Polarization in the Timing

and Trajectories to Motherhood

motherhood that does not pass through any of the other events. (The small number of respondents belonging to high social status in the oldest cohort shown in Table 2A does not allow the tracing of trajectories beyond the first transitions.)

\section{Preferred Pathway to Motherhood most Common mainly among High Status Women}

The "normatively" preferred pathway to motherhood, that is, graduation $\rightarrow$ work $\rightarrow$ marriage $\rightarrow$ motherhood trajectory (A1 in Tables $2 \mathrm{~A}, 2 \mathrm{~B}$ and $2 \mathrm{C}$ ) is mainly followed by women with high social status. Tables $2 \mathrm{~B}$ and $2 \mathrm{C}$ show that the final probabilities of this trajectory are the highest for high status women in the mid and youngest cohorts at 0.21 and 0.24 respectively. The probabilities of this trajectory are much lower for lower status women but these have increased over cohorts. In the oldest cohort, the probability among low status women of going through this trajectory is only 0.05 (A1 in Table $2 \mathrm{~A}$ ) but the probability increased to 0.08 in the mid cohort (Table 2B) and to 0.12 in the youngest cohort (Table 2C) $)^{5}$.

That women of high social status have greater likelihood of graduating from post-secondary education before marriage is also seen from the next most common trajectory of high status women, particularly for the youngest cohort; working prior to completion of post-secondary education -- that is, the work $\rightarrow$ graduation $\rightarrow$ marriage $\rightarrow$ motherhood trajectory (B1 in Tables $2 \mathrm{~A}-2 \mathrm{C}$ ). In the youngest cohort, this probability is 0.17 among high status women but only 0.09 among low status women. The combined probabilities of these two trajectories (graduation $\rightarrow$ work $\rightarrow$ marriage $\rightarrow$ motherhood and the work $\rightarrow$ graduation $\rightarrow$ marriage $\rightarrow$ motherhood) are twice as high among high status women as among low status women $(0.41$ versus 0.21$)$. The corresponding probability is 0.34 as against 0.15 in the mid cohort (see next to last row of Tables $2 \mathrm{~B}$ and $2 \mathrm{C}$ ).

\section{Different Trajectories among Lower Status Women}

Most women belonging to low or middle status enter the labour force without first finishing a tertiary education; they then marry and become mothers. This work $\rightarrow$ marriage $\rightarrow$ motherhood trajectory (B2 in Tables 2A-2C) is the most common among lower status women in all three cohorts; however, the probabilities, though high, have decreased over cohorts. The probability of going through this trajectory among women with low social status, for example, is 0.35 in the oldest cohort, remains the same for the mid-cohort, but decreases to 0.20 in the youngest cohort. Not surprising, the probability of this trajectory 
among high status women is lower.

A trajectory that does not go through either education or work is also more common among the low status women. However, this marriage $\rightarrow$ motherhood trajectory ( $\mathrm{C} 1$ in Tables $2 \mathrm{~A}-2 \mathrm{C})$ has also significantly decreased over cohorts. Among the low status women, for example, a quarter of women in the oldest cohort went through this trajectory. This was almost halved in the mid-cohort (to 0.14 ) and cut by half again (to 0.07) in the youngest cohort. A similar trend occurred among middle status women - with the probability decreasing from 0.19 in the oldest to 0.05 in the youngest cohort. The common pathway among older cohorts of women of marrying and becoming mothers without going through post-secondary education or work is no longer prevalent among the younger cohorts. As expected, this trajectory is followed least by women of high status in all cohorts.

\section{Becoming Mothers without Marrying most likely among Low Status Women}

While the proportion of women who graduate from post-secondary education before becoming mothers has increased over cohorts, the other pathways that have become more widespread among the younger cohort are those that do not go through marriage; that is, most likely, motherhood occurring in cohabiting unions. The work $\rightarrow$ motherhood trajectory (B3 in Tables 2A-2C) among women with low status, for example, has increased from 0.05 in the oldest cohort to 0.13 in the youngest cohort, which also occurred among women with middle status. In contrast, this trajectory has a very low probability ( 0.03 and 0.04 in the mid and youngest cohort respectively) among high status women.

This trend among lower status women becomes a greater concern when the probability of becoming mothers without first completing post-secondary education, working, or marrying (row D in Tables 2A-2C) is considered. The probability of this trajectory has almost doubled among low status women (from 0.06 to 0.11 ) over cohorts. As one might expect, the probability of making this transition is low among high status women, though it also did increase from cohort to cohort (from 0.02 to 0.05 ). One might wonder what subsequently happens to these women who proceed through this trajectory. As with the other results, our analysis shows that the transitions following motherhood vary by cohort and social status (results not shown here). For the two older cohorts, the most common transition after motherhood is marriage for all social statuses. In the youngest cohort, the most common transition among the two lower statuses is to start of regular work; whereas for women of high status, completion of post-secondary education is the most common transition after motherhood, 
Zenaida R. Ravanera and Fernando Rajulton

though the probability of starting regular work comes very close. (Note, however, that the number of women who go through this trajectory, particularly among high status women, is small.)

\section{Life Courses have their own Momentum}

As noted by Rindfuss, Morgan and Swicegood (1988), a life course trajectory has its own momentum and carries with it opportunities and constraints that, in turn, influence the timing of first birth. This is validated to a great extent by the results of our trajectory analysis. For instance, when the first transition is graduation from post secondary education, the most likely second transition is start of regular work [see A1 (ii) in Tables $2 \mathrm{~A}-2 \mathrm{C}$ ] rather than marriage or motherhood. Similarly, a transition to marriage is most likely followed by a transition to motherhood [see, for example, B2 (iii) in Tables 2A-2C].

However, this seeming inevitability of a life course trajectory has changed over cohorts. For example, women in the oldest cohort who did not complete postsecondary education but went directly to regular work were most likely to have marriage as their next transition. In the youngest cohort, however, more women move on to completing post-secondary education after start of regular work. Among the low status women, the probability of marriage is 0.74 in the oldest cohort but only 0.42 in the youngest [B2 (ii) in Tables $2 \mathrm{~A}-2 \mathrm{C}$ ]. In contrast, the probability of post-secondary graduation is 0.14 in the oldest cohort and 0.29 in the youngest [B1 (ii) in Tables 2A-2C]. The change in momentum of the life course is also seen in the total final probabilities of transition to motherhood through the six most common trajectories shown in Tables $2 \mathrm{~A}$ to $2 \mathrm{C}$ (last row). For low status women, for example, the total decreased from 0.81 in the oldest cohort to 0.72 in the youngest. The decrease in the totals for all social statuses is an indication that there are more trajectories to motherhood among today's young women than the common ones (shown in Table 2) that were traversed by the older cohorts.

There are variations by social status as well. For women of higher status, for example, marriage is not necessarily followed by motherhood, particularly if they have not as yet completed post-secondary education or have had regular work. (See, B2 (iii) and C1 (ii) in Tables 2B and 2C). That women of high status are more likely to pursue trajectories other than those shown in Table 2 is also seen in the totals of final probabilities of motherhood. Among women belonging to the mid cohort, for example, these final probabilities are 0.77 for the low but only 0.62 for high status women (last row of Table $2 \mathrm{~B}$ ). 
Social Status Polarization in the Timing

and Trajectories to Motherhood

\section{Age at onset of Motherhood is largely determined by the Number of Prior Transitions}

The fewer the number of events experienced prior to the birth of first child, the younger the age at onset of motherhood. This is because the time spent for other pursuits, mainly for education and work, serves as a delaying factor. Thus, for all cohorts and all social statuses, those whose first transition is to first birth start motherhood the earliest, while those who go through the other three events of graduation from post-secondary education, start of regular work, and marriage become mothers the latest. [Compare, for example, the 'duration' column of D with $\mathrm{A} 1(\mathrm{v})$ in Tables $2 \mathrm{~A}-2 \mathrm{C}]$. The differences range from 6 to 10 years.

Remarkable, however, is the time spent between marriage and motherhood in the two younger cohorts. The duration is longest among those who go through post-secondary education, mostly about 3 years; and shortest among those who directly marry, with about a year and a half separating marriage from motherhood. [Compare A1 (iv) with C (ii) in Tables 2B and 2C]

There are dissimilarities by social status as well. In general, women with high social status start motherhood at older ages than low status women though they may have gone through the same trajectory. However, the differences are not large. In the youngest cohort, for example, women with low social status who go through the graduation $\rightarrow$ work $\rightarrow$ marriage $\rightarrow$ motherhood trajectory become mothers at age 28.7, whereas high status women do so at age 29.4.

\section{Discussion}

We sum up some of our findings as follows:

- The increase in age at first motherhood over cohorts was led mainly by women of high social status in the 1941-60 birth cohort.

- The differences by social status in the ages at the onset of motherhood are traceable through other events that happen in early life. The delay in onset of motherhood could be partly accounted for by delays in such events as completion of schooling (though information on this from the survey is limited), start of regular work, first union, and first marriage.

- Women with high social status are more likely to go through the normatively preferred trajectory that includes completion of postsecondary education prior to motherhood. 
- Women with lower social status are more likely to go through shorter routes to motherhood, including the trajectory that bypasses postsecondary education, regular work, and marriage.

- The timing of motherhood is largely influenced by the number of prior life course events experienced. However, though differences are not large, women of high social status tend to become mothers later than women of lower status even if they go through the same trajectory.

The literature abounds with explanations for the decline of fertility, some of which could be used to explain also the increasing age at childbearing, or in particular, the start of parenthood. The most common explanation proffered is that of economic rationality (see for example, Easterlin, 1978; Kaplan, Lancaster and Anderson, 1998; Adesera, 2005). Education requires investment in resources including time and money, which then requires well-paying jobs to recoup the investment. With higher education and paid employment, the opportunity cost of having children increases. The perceived high cost of 'high quality' children coupled with the decline in material benefits from children provide more incentives to delay parenthood. The differentials in timing and trajectories suggest that the economic rationale for delaying entry may be stronger among high status women.

Canadian women have increasingly acquired higher education and have entered the labour force in greater proportions since the 1970s (Beaujot, 2000). However, our findings show that the delay in the start of parenthood began primarily among women with high social status in the 1941-60 birth cohort. Women in this cohort are baby boomers, many of whom received their postsecondary education in the late 1960s and in the 1970s. In the early years of expansion of opportunities for higher education and employment, the beneficiaries were mainly those belonging to high social status as they may have had the resources to take advantage of those opportunities. That opportunities for higher education and work have expanded in subsequent decades to include those with lower status can be gleaned from the results of the trajectory analysis but the differences in the trajectories to motherhood by social status also show that the inequality of opportunities has not been eliminated.

The timing of fertility is not just a product of rational economic calculation but is also influenced by cultural factors such as attitudes and values. Underpinning the second demographic transition, for example, is the change of values, mainly toward individualism and desire for self-fulfillment (Lesthaeghe, 1995). One's background imparts shared values or attitudes regarding fertility and timing of parenthood through socialization (Rindfuss, Morgan, and Swicegood, 1988; Michael and Tuma, 1985). Our own hazards analysis of the onset of motherhood 
(not shown here) indicates that values do influence the start of parenthood ${ }^{6}$. The age at onset of motherhood among those who profess a religion is earlier compared to those who do not belong to any religion. Furthermore, those who regard family-related values (such as having a lasting relationship, having a child, and being married) as important to happiness are more likely to parent early; whereas those who give importance to a paying job (job-related value) are more likely to delay entry into motherhood.

Change of values is thus another plausible explanation for the increase in age at motherhood between cohorts and the timing divergence by social status in the onset of motherhood. As shown in Panel C of Appendix Table 2, the oldest cohort of women had the highest score on the indicator of family-related values and the mid-cohort of women, the lowest. If family values were the only influence on age at parenthood, the youngest cohort of women would start motherhood earlier as they seem to hold family values more highly than the mid-cohort (Panel C, Appendix Table 1). However, the importance they place for a paying job is much higher than those of the two previous cohorts, which is probably why the delay in the onset of motherhood continues.

We have not exhausted all possible reasons for the increasing delays in the onset of motherhood and for the differentials by social status. Our hope, however, is that our attempt at situating the onset of motherhood in a life course framework and tracing the various trajectories would contribute to the continuing search for explanations of the decline in fertility in modern societies (for latest attempts at understanding fertility decline, see for example, Caldwell and Schindlmayr, 2003; Hakim, 2003; McDonald, 2000).

\section{Conclusions}

To the question of whether there is a polarization by social status of the life course leading to the onset of motherhood, the answer provided by our analysis is "yes". However, this polarization is not a recent phenomenon; the timing and trajectories of life course events have differed by social status for all cohorts included in our analysis, the biggest change having occurred in the 1941-60 birth cohort. Moreover, social status differences need to be viewed in the context of social mobility. There has been a shift towards higher status over cohorts in the population. For example, the proportion of women with low social status in the $1922-40$ birth cohort is $45 \%$ while it is $17 \%$ in the $1961-80$ birth cohort. The middle class expanded from $31 \%$ in the oldest to $47 \%$ in the youngest cohort; and the high status from $4 \%$ to $19 \%$ (see Descriptive statistics shown in App. Table 3). 
The recent concern over the bifurcation of fertility is possibly triggered by the increasing conspicuousness of those who become parents early. The general affluence of the population and the greater social mobility through education make noticeable those who are "left behind". With high rates of divorce and separation, the negative consequences of early entry into family formation, specifically marital instability and lone parenthood, have become more widespread. And the weakening of age norms and the increase in age at experience of family events (including the start of marital union and parenthood) have made the timing of transitions more variable (Settersten and Hagestad, 1996; Ravanera, Rajulton, and Burch, 2004), thus making those who make early transition to parenthood more visible.

However, while viewing the polarization of the life course in the perspective of social mobility, our study does indicate that inequality of opportunities accentuates the differences in the timing and trajectories to motherhood. Interventions that would diminish the inequalities, say, in the access to higher education and subsequently, to employment, would most likely have the effect of reducing the differentials in the timing of entry to parenthood as well. Reducing the disparities in opportunities could mean, at the population level, a greater delay in the onset of motherhood, which would, in turn, lead to even lower fertility than the current level. This accentuates the importance for interventions that facilitate the balancing of family and work life such as those related to family benefits and the provision of child-care services (for a detailed discussion of the various types of interventions that relate to fertility, see Beaujot, 2004; Pampel, 2001; Gauthier, 1996; Gauthier and Hatzius, 1997; Kaufmann et al, 2002).

\section{Acknowledgement:}

This paper is an outcome of a project, "The Family, Community, and Health in the Context of Economic Change" funded by Health Canada. The authors also thank the two anonymous reviewers for their suggestions.

\section{End Notes:}

1. Mother's education was ranked as low (some high school or lower), middle (high school graduate or some post-secondary) or high (post-secondary graduate or higher). And, based on the prestige scores established by Goyder, Thompson, and Dixon (2003) and applied to the Standard Occupational Classification provided in the survey, father's occupation was ranked as follows: Low (Sales and Services Occupations, Occupations 
Unique to Processing and Manufacturing, Occupations Unique to Primary Industry), Middle (Trades, Transport, and Equipment, Business, Finance, and Administrative Occupation, Artistic, Culture, Recreational, Sport, and Occupations in Social Sciences, Education) and High (Management Occupations, Natural and Applied Sciences, and Health Occupations). The two rankings were added and the final social status rank was assigned as follows: low $(1,2)$, middle $(3,4)$, high $(5,6)$. A score of one is possible when information on mother's education is missing. Cases where both mother's education and father's occupation are missing were assigned to a "Missing" category. Life table analysis (but not the trajectory analysis) was done for this missing category though results are not shown in the tables.

2. This is a 19-year birth cohort. We would have preferred to consistently use a 20 -year birth cohort, that is 1921-40, but the GSS2001 Public Use Microdata file collapsed those 80 years old and over into one category (born in 1921 and earlier).

3. The differences in median ages at birth of first child by cohort and by social status discussed in the text are all statistically significant at lower than $1 \%$ level as indicated by a comparison of survival experience using the Wilcoxon-Gehan statistic.

4. Right censoring, which is more relevant for the youngest cohort consisting of women as young as age 20 , would underestimate the final probabilities particularly for the onset of motherhood and for higher status women who are more likely to experience family life events at older ages.

5. As can be seen from the tests of differences between cohorts and between social statuses (Appendix Table 3, and footnotes to Table 2), all the changes discussed in the text are statistically significant.

6. A proportional hazards analysis shows that a number of factors (including family structure, respondent's education, income, migration status, and region of residence) influence the timing of motherhood. However, the differences by social status for each cohort remain even after inclusion of these variables in the models. Results of the proportional hazards analysis can be obtained from the authors upon request. 
Zenaida R. Ravanera and Fernando Rajulton

\section{References:}

Adsera, Alicia, 2004. "Changing fertility rates in developed countries: The impact of labor market institutions," Journal of Population Economics 17 (1): $17-43$.

Beaujot, R. 2000. Earning and Caring in Canadian Families. Peterborough, ON. Broadview Press.

Beaujot, R. 2004. Delayed life transitions: Trends and implications. Vanier Institute of the Family Contemporary Family Trends Series. http://www.vifamily.ca/library/cft/delayed life.pdf. Accessed on May 10, 2004.

Bianchi, S.M. 2000. "Maternal employment and time with children: Dramatic change or surprising continuity," Demography 37(4): 401-414.

Booth, A., A.C. Crouter, and M.J. Shanahan (eds). 1999. Transitions to Adulthood in a Changing Economy: No Work, No Family, No Future? Westport: Praeger.

Boyd, M. and D. Norris. 1999. "The crowded nest: Young adults at home," Canadian Social Trends 52: 2-5.

Caldwell, J.C. and T. Schindlmayr. 2003. "Explanations of the fertility crisis in modern societies: A search for commonalities," Population Studies 57(3): 242-263.

Elder, G.H. Jr. 1978. Family history and the life course. In T. Hareven (ed) Transitions: The Family and the Life Course in Historical Perspective; Academic Press. Pp.17-64.

Easterlin, R.A. 1978. The economics and sociology of fertility: A Synthesis. In Charles Tilly (ed.) Historical Studies of Changing Fertility Princeton: Princeton University Press. Ch.2.

Fussell, E. 2002. The transition to adulthood in aging societies. In F.F. Furstenberg, Jr. (ed) Early Adulthood in Cross-National Perspective. Thousand Oaks, CA: Sage Publications. Pp. 16-39.

Gauthier, A.H. 1996. The state and the family: A comparative analysis of family policies in industrialized countries. New York: Oxford University Press. 
Social Status Polarization in the Timing

and Trajectories to Motherhood

Gauthier, A. H. and J. Hatzius. 1997. "Family benefits and fertility: An econometric analysis," Population Studies 51: 295-306.

Goyder, J., M.E. Thompson and S. Dixon. 2003. Scaling the major groups of the National Occupational Classification. Paper presented at the 2003 Annual Meeting of the Canadian Sociology and Anthropology Association. Halifax.

Grabb, E. G. 2002. Theories of Social Inequality. Fourth Edition. Scarborough, Ontario: Nelson Thompson Learning.

Hakim, C. 2003. "A new approach to explaining fertility patterns: Preference theory," Population and Development Review 29(3): 349-374.

Hogan, D.P.1980. "The transition to adulthood as a career contingency," American Sociological Review 45:262-76

Hogan, D.P. 1981. Transitions and Social Change: The Early Lives of American Men. NY: Academic Press.

Hogan, D.P. and N.M. Astone. 1986. "The transition to adulthood," Annual Review of Sociology 12: 109-130.

Kaplan, H., J.B. Lancaster and K.G. Anderson. 1998. Human Parental Investment and Fertility: The Life Histories of Men in Albuquerque. In A.Booth and A.C. Crouter (eds) Men in Families: When Do They Get Involved? What Difference Does It Make? Mahwah, New Jersey: Lawrence Erlbaum. Pp. 55-109.

Kaufmann, F.X. 1988. Familie und modernität (Family and modernity) in K. Lüscher, F. Schulteis, and M. Wehrspaun (eds). Die 'postmoderne' Familie. Familiale Strategien und Familienpolitik in einer Überganszeit. Unversitätsverlag Konstaz, Konstanz: 391-415.

Kaufmann, F.X., A. Kuijsten, H.J. Schulze, and K. P. Strohmeier (eds). 2002. Family Life and Family Policies in Europe. Vol. 2. New York: Oxford University Press.

Lapierre-Adamcyk, E., C. Le Bourdais and K. Lehrhaupt, 1995. « Le départ du foyer parental des jeunes Canadiens nés entre 1921 et 1960,» Population 50(4-5): 1111-1136. 
Zenaida R. Ravanera and Fernando Rajulton

Lesthaeghe, R. 1995. The second demographic transition in Western countries: An interpretation. In Mason, K. O. and A.M. Jensen (eds) Gender and Family Change in Industrialized Countries. New York: Oxford University Press. Pp. 18-62.

Lochhead, C. 2000. "The trend toward delayed first childbirth: Health and social implications," Isuma (Autumn): 41-44.

Lochhead, C. 2001. Does age at first birth matter? Parenting capacity and child heath and development. Report prepared for Policy Division, Policy, Planning and Priorities Directorate, Health Policy and Communications Branch, Health Canada.

Marini, M.M. 1984a. "The order of events in the transition to adulthood," Sociology of Education 57(2): 63-84.

Marini, M.M. 1984b. "Age and sequencing norms in the transition to adulthood," Social Forces 63(1): 229-44.

Martin, S. 2000. "Diverging fertility among U.S. women who delay childbearing past age 30," Demography 37(4): 523-533.

McDonald, P. 2000. "Gender equity theories of fertility transition," Population and Development Review 26(3); 427-439.

Michael, R. and N.B. Tuma. 1985. "Entry into marriage and parenthood by young men and women: The influence of family background," Demography 22(4): 515-544.

Pampel, F. C. 2001. The Institutional Context of Population Change: Patterns of Fertility and Mortality across High-Income Nations. Chicago: University of Chicago Press.

Rajulton, F. 2001. "Analysis of life histories: A state space approach," Canadian Studies in Population 28:341-59.

Ravanera, Z. F. Rajulton, and T. K. Burch.1998. "Early life transitions of Canadian women: A cohort analysis of timing, sequences, and variations," European Journal of Population 14: 179-204. 
Social Status Polarization in the Timing and Trajectories to Motherhood

Ravanera, Z.R. F. Rajulton, T.K. Burch and C. Le Bourdais. 2002. "The early life courses of Canadian men: Analysis of timing and sequences of events," Canadian Studies in Population 29: 293-312.

Ravanera, Z., F. Rajulton, and T.K. Burch. 2003. "Early life transitions of Canadian youth: Effects of family transformation and community characteristics," Canadian Studies in Population 30(2): 327-354.

Ravanera, Z., F. Rajulton, and T.K. Burch. 2004. "Patterns of age variability in life course transitions," Canadian Journal of Sociology 29(4): 527-542.

Rindfuss, R.R., S.P. Morgan, and G. Swicegood. 1988. First Births in America: Changes in the Timing of Parenthood. Berkeley: University of California Press.

Ryder, N. B.1965. "The cohort as a concept in the study of social change," American Sociological Review 30: 843-61.

Schulze, H. J. and H. Tyrell. 2002. What happened to the European family in the 1980s? The polarization between the family and other forms of private life. In Kaufmann, F.X., A. Kuijsten, H.J. Schulze, and K. P. Strohmeier (eds). Family Life and Family Policies in Europe. Vol. 2. New York : Oxford University Press. Pp. 69-119.

Settersten, R. A. Jr. and G. O. Hagestad. 1996. "What's the latest? Cultural age deadlines for family transitions," The Gerontologist 36(2): 178-188.

Shanahan, M. J. 2000. "Pathways to adulthood in changing societies: Variability and mechanisms in life course perspective," Annual Review of Sociology 26: 667-92.

Statistics Canada. 2003. General Social Survey of Canada, 2001. Cycle 15: Family History. Public Use Microdata File Documentation and User's Guide. Cat. No. 12M0015GPE. Ottawa: Ministry of Industry. 
Zenaida R. Ravanera and Fernando Rajulton

App. Table 1: Descriptive Statistics of Women in the Sample 2001 General Social Survey

\begin{tabular}{|c|c|c|c|c|}
\hline & $1922-40$ & $1941-60$ & $1961-80$ & All \\
\hline \multicolumn{5}{|l|}{ Social Status } \\
\hline Low & 45.2 & 30.3 & 17.2 & 27.7 \\
\hline Middle & 31.3 & 45.3 & 47.2 & 43.4 \\
\hline High & 4.3 & 9.6 & 18.7 & 12.4 \\
\hline Missing & 19.3 & 14.9 & 16.9 & 16.6 \\
\hline $\mathrm{N}$ & 2224 & 4646 & 4909 & 11779 \\
\hline \multicolumn{5}{|l|}{ Respondent's Education } \\
\hline Some High School & 48.5 & 20.4 & 9.3 & 21.0 \\
\hline High School Graduate & 17.4 & 22.0 & 17.2 & 19.1 \\
\hline Some College & 5.7 & 10.4 & 16.1 & 11.9 \\
\hline College/University Grad & 28.4 & 47.3 & 57.4 & 48.0 \\
\hline $\mathrm{N}$ & 2169 & 4601 & 4877 & 11647 \\
\hline \multicolumn{5}{|l|}{ Personal Income } \\
\hline Less than $\$ 20,000$ & 36.4 & 31.2 & 36.8 & 34.5 \\
\hline$\$ 20,000-\$ 49,999$ & 14.9 & 30.5 & 34.4 & 29.2 \\
\hline$\$ 50,000$ or higher & 2.4 & 11.5 & 7.0 & 7.9 \\
\hline Missing & 46.2 & 26.7 & 21.8 & 28.4 \\
\hline $\mathrm{N}$ & 2224 & 4646 & 4908 & 11778 \\
\hline \multicolumn{5}{|l|}{ Religion } \\
\hline No Religion & 6.1 & 12.4 & 19.1 & 14.0 \\
\hline Roman Catholic & 44.2 & 43.6 & 43.6 & 43.7 \\
\hline Protestant & 40.9 & 35.3 & 26.0 & 32.5 \\
\hline Other Religion & 8.9 & 8.7 & 11.3 & 9.8 \\
\hline $\mathrm{N}$ & 2224 & 4645 & 4908 & 11777 \\
\hline \multicolumn{5}{|l|}{ Migration Status } \\
\hline Born in Canada & 75.9 & 78.2 & 79.2 & 78.2 \\
\hline Immigrant & 24.1 & 21.8 & 20.8 & 21.8 \\
\hline $\mathrm{N}$ & 2204 & 4618 & 4876 & 11698 \\
\hline \multicolumn{5}{|l|}{ Region } \\
\hline British Columbia & 13.4 & 13.6 & 13.1 & 13.4 \\
\hline Atlantic & 7.5 & 7.9 & 7.6 & 7.7 \\
\hline Quebec & 25.1 & 25.4 & 23.4 & 24.5 \\
\hline Ontario & 39.0 & 37.7 & 39.4 & 38.6 \\
\hline Prairies & 15.0 & 15.3 & 16.6 & 15.8 \\
\hline $\mathrm{N}$ & 2223 & 4646 & 4907 & 11776 \\
\hline \multicolumn{5}{|l|}{ Marital Status } \\
\hline Married & 57.6 & 68.0 & 48.0 & 57.7 \\
\hline Common-Law & 1.3 & 8.3 & 16.6 & 10.4 \\
\hline Sep/Div/Wid. & 36.3 & 17.0 & 6.4 & 16.2 \\
\hline Single & 4.8 & 6.7 & 28.9 & 15.6 \\
\hline $\mathrm{N}$ & 2215 & 4642 & 4891 & 11748 \\
\hline
\end{tabular}


Social Status Polarization in the Timing and Trajectories to Motherhood 
Zenaida R. Ravanera and Fernando Rajulton

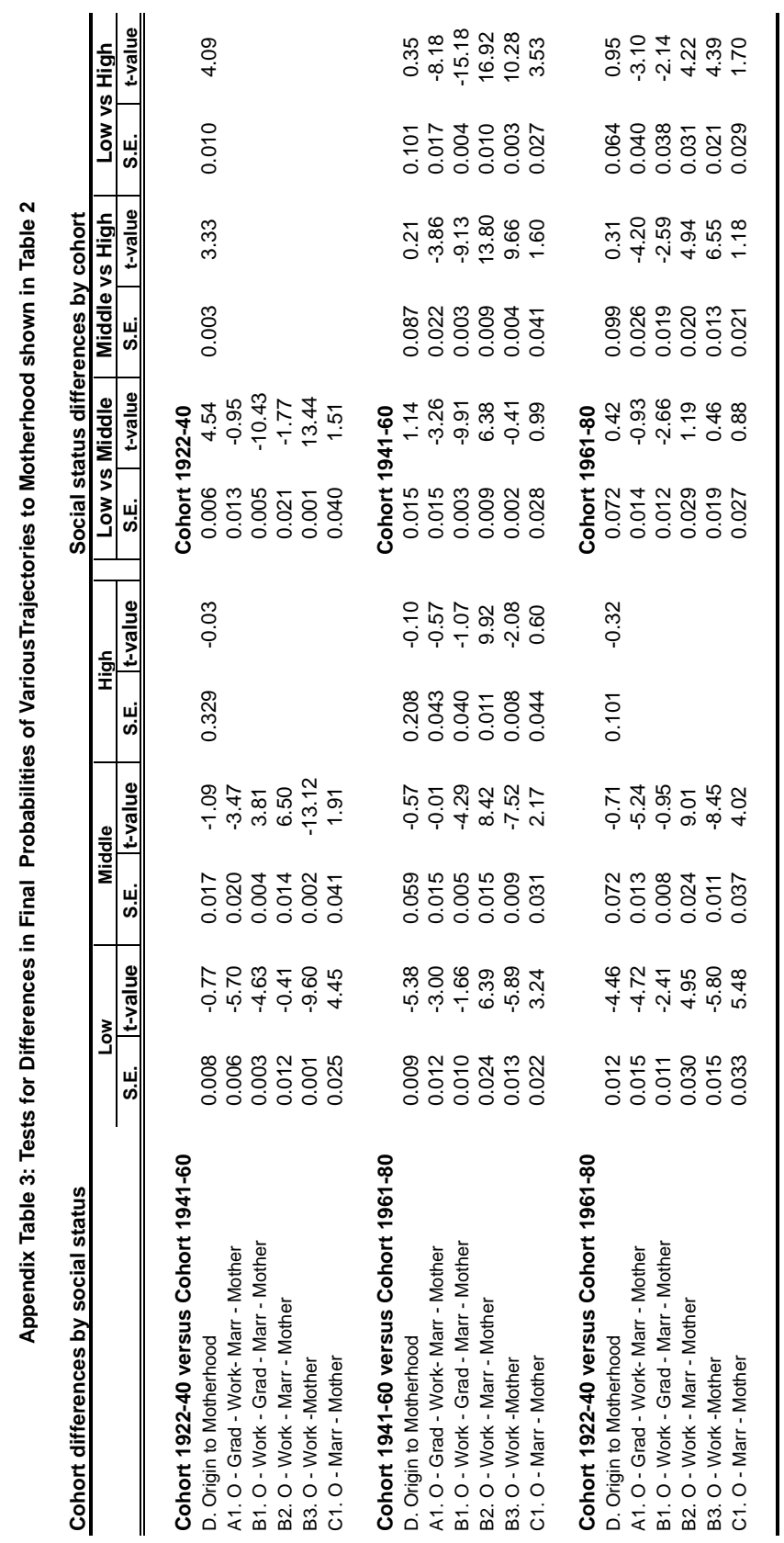

